\title{
Plural indefinite descriptions with unos and the interpretation of number ${ }^{1}$
}

\author{
HELENA LOPEZ PALMA
}

Abstract

It has been noticed that indefinite descriptions with the Spanish determiner unos (plural-"one") have a group denotation (Villalta 1994). That meaning has been explained within DRT (Laca and Tasmowski 1996, Gutiérrez Rexach 2001). Unos introduces a group referent variable in the discourse, which is associated to an atomic condition and does not trigger box-splitting (Gutierrez Rexach 2001). However, the group interpretation is unstable, and there are cases in which unos-DPs may have an individual reading too. We suggest that instability is best understood as an epistemic fact. Unos is not a semantic determiner of the plural noun that follows it but it is composed with a covert group-denoting noun, which restricts the variable domain to sets of groups. The plural noun denotes the member's class and is related to the covert group term through a group-constitute function (Barker 1992). The group interpretation is unstable because it relies on our implicit knowledge of a covert group-denoting nominal head. The variability in the group interpretation also shows the role of perception in processing groups. We propose an explanation of the instability of unos in terms of Kratzer's version of a Skolem Choice Function. Unos denotes a Perspectival Choice Function that combines with a predicate denoting a set of groups and returns a unique group. We use the perspectival argument to represent the holder of the beliefs from which the implicit meaning is inferred. When the perspectival argument is underspecified, the unos-phrase denotes a

1. I'd like to express my gratitude to Amor Admella, Hans-Jörg Bibiko, Tonia Bleam, Laura Brugè, Patricia Cabredo Ofherr, Violeta Demonte, Carmen Dobrovie Sorin, Bernard Fradin, Sven Grawunder, Jacqueline Guéron, Danièle Godard, Alain Kihm, SongNim Kwon, Brenda Laca, Jean Lowenstamm, Iulen Manterola, Dorian Roehrs, Donald Stilo, Emiliana Tucci, Anne Zribi-Hertz and the anonymous reviewers. A version of this paper was presented in a Seminar at LLF, University Paris 7, May 2004, and at WECOL, USC, LA, November, 2004. 
fuzzy group, which we dub a cluster. When it is anchored to the speaker, the content of the cluster becomes transparent and the distributive reading of the group may arise. We extend the Spanish case to Galician and Catalan.

\section{A number mismatch problem}

Using the cardinal number "one" as an indefinite determiner for singular count nouns is a very common referring mechanism found in many unrelated natural languages (Givon 1981, Haspelmath 1997, Dryer 2005). ${ }^{2}$ Dryer (2005) reports the use of "one" for the singular indefinite article in Lezgian (Caucaso), Meithei (Tibeto-Butman), Limbu (Tibeto-Burman, Nepal), Pa'a (Chadic, Nigeria), Remo (Munda, India). However, generalizing "one" as an indefinite determiner for the plural is not as frequent. The plural-"one" indefinite article is found in Romance Languages: it is used in Catalan (uns, unes), Old French (uns, unes), Galician (uns, unhas), Portuguese (uns, umhas), Romanian (unii, unele) and Spanish (unos, unas). But not all Romance languages have extended the use of "one" as indefinite article to the plural. Italian has developed a "partitive article" (dei, della) to convey a plural indefinite meaning similar to unos-DPs, and Modern French has substituted the old plural indefinite article uns, unes by a partitive article des. ${ }^{3}$ The following sentences illustrate the use of plural-"one" as indefinite article: ${ }^{4}$

Els mariners van amuntegar unes caixes al
the sailors piled
moll.
docks
'The sailors piled a group of boxes on the docks.'
Uns noivos están a falar no outeiro. ${ }^{5}$ (Galician)
ONE.PL couple are P talk on_the hill
'A couple are talking on the hill.'

2. The reason could lie in the close relation between counting and referring. Making reference to discrete entities may start as a counting act. The basic unit used for counting is obtained from mapping oneself onto other entities. After several counting acts, an abstract concept of unit is obtained. Then, the unit thus excerpted may be used for epistemic reference.

3. The distribution of the French and the Italian partitive article, though, is not completely equivalent to the distribution of the Romance plural-"one" indefinite article, because it also appears in contexts where Iberian Romance Languages would use a bare plural noun.

4. The following abbreviations will be used: ACC accusative; CL clitic; DEF definite article; DP determiner phrase; F feminine; GEN genitive; IND indicative; LOC locative; NP nominal phrase; P preposition; PL plural; PST past tense; QP quantifier phrase; SG singular; SUBJV subjunctive.

5. The phonetic evolution of Galician plural masculine uns, instead of unos, proves that the cardinal was used as an indefinite article from the origins. 
"calças de buen panno en sus camas metió, hoses of good cloth in his legs put 'he (the Cid) covered his legs with hoses of good cloth'

sobr'ellas unos çapatos que a grant huebra son;" over_them ONE.PL shoes that of great work are 'he put over them a pair of shoes that are a great work.' (Song of Mio Cid, 1207: vv 3085/3086) (Spanish)

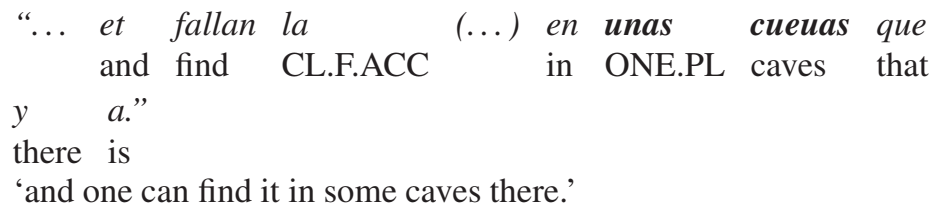

ONE.PL men

(Malison 1987: 251)

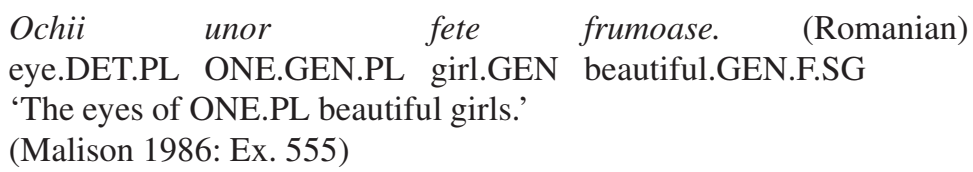

The use of "one" as a plural indefinite article does not seem to be constrained to a particular family of languages. It appears in languages that belong to unrelated family groups, such as Basque, Lavukaleve (Dryer 2005) or Miskito (Salamanca 1988, Plank 1994):

Basque: 6

(7) Ibai.an badaude emakume bat.zuk

river.LOC are woman ONE.PL

'There are a group of women in the river.'
Katu bat.zuk jardinean lotan daude.
cat ONE.PL garden.LOC dream are

'A group of cats are sleeping in the garden.'

Miskito indefinite determiner (Salamanca 1988, Plank 1994):

(9)

$$
\begin{aligned}
& \text { aras kum } \\
& \text { horse one } \\
& \text { 'a horse' }
\end{aligned}
$$

6. Julen Manterola, personal communication. 


\section{Helena Lopez Palma}

(10) aras nani

horse PL

'horses'

aras siksa nani kum.kum ${ }^{7}$

horse black PL ONE.PL

'a group of black horses'

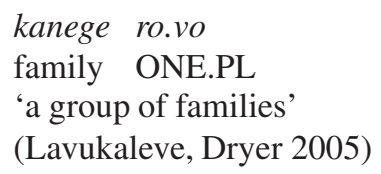

Czech (singular mas/fem/neuter: jeden, jedna, jedno; plural: jedny), Russian (singular mas/fem/neuter: odín, odná, odnó; plural: odní) and Bulgarian (singular mas/fem/neuter: edin, edna, edno; plural: edni) have morphological plural number marking on the numeral "one":

jedn.y nuzky

(Czech)

ONE.F.PL scissors.F

'one pair of scissors'

odni ochki

(Russian)

ONE.PL glasses.PL

'one pair of glasses'
Edni
kotki igraiat na dvora.
ONE.PL cat playing in yard
(Bulgarian)
'A group of cats are playing in the yard.'

The uncommon use of plural-"one" as indefinite article seems to be a natural fact, given the contradiction that results from combining the unit-denoting numeral word with a plural-denoting nominal expression. One way in which natural languages seem to have solved that contradiction is by reinterpreting plural-"one" as a collectivizing word. That seems to be the solution adopted by Iberian Romance languages.

The collective meaning of indefinite descriptions with plural-"one" has been studied for Spanish unos by Villalta (1994), Laca and Tasmowski (1996), and Gutiérrez Rexach (2001). They propose that unos is a collectivizing determiner

7. Specificity is marked in Miskito by means of the definite article $b a$, which may be combined with kum:
(i) aras nani kumkum ba
horse PL ONE.PL DEF
'the horses'


that contributes the group meaning obtained in unos-DPs. They make a contrastive study of indefinite descriptions with the determiners unos and algunos ("some".PL), which may appear in DPs that are ambiguous between a collective and a distributive interpretation. They argue that the group-denoting unosphrase crucially differs from the collective interpretation of the algunos-phrase in that unos seems to have an inherent lexical group meaning that algunos lacks.

In this paper I propose an analysis for the semantics of group-denoting unosDPs that aims at giving a general account for group expressions, and which takes into consideration the role of perception in fuzzy group calculations.

The structure of the paper is as follows: In Section 2 we will consider some of the empirical facts adduced by Villalta, Laca and Tasmowski, and Gutiérrez Rexach in their analysis of unos as a "collectivizer" determiner, and we will review the account they propose to capture that meaning. After, we will consider some of the problems for their analysis and we will suggest a modifying proposal that could solve those difficulties. In Section 3 we will study the problem of the number mismatch in the unos-phrase. We will argue that unos-DPs differ from ambiguous weak/strong algunos-DPs in that the unos-phrase denotes a group that is unstable, and does not describe a plural individual which is ambiguous between a collective and a distributive interpretation. We will, then, propose that unos is the semantic determiner of a null nominal head, which is responsible for restricting the domain of the variable to group sorts. In Section 4 we will apply Kratzer's (1998) concept of Perspectival Choice Function to calculate the epistemic interpretation of the plural-"one" indefinite determiner. In Section 5 we will use the perspectival choice function analysis to give an epistemic account of the distributive reading of the group denoted by "unos-DP".

\section{Some relevant data and previous accounts}

Villalta (1994), Laca and Tasmowski (1996), and Gutiérrez Rexach (2001) have observed for Spanish that plural indefinite descriptions with the determiner unos ('ONE'.PL) denote a group entity. Unos crucially differs in this semantic value from other plural indefinite determiners, such as cardinals or the existential plural quantifier algunos ("some"), in that the unos-phrase denotes a plural referent that is interpreted as a unique plural individual with an opaque part structure, and not as a cumulative sum of atoms. The following data supports their view:

1. Unos-DPs cannot be the relevant argument of Individual-level predicates that denote inherent properties of the individual entities of a class. Individuallevel predicates select individual-denoting strong DPs (Milsark 1977, Ladusaw 
1994, Dobrovie-Sorin 1997), and weak indefinite descriptions with unos do not contribute such an argument. By contrast, algunos-DPs, which, like "some"DPs, are ambiguous between a weak and a strong reading, may appear as the relevant argument of those predicates on the strong reading. The algunosphrase has, on such an interpretation, a presuppositional meaning equivalent to "some of the NP":
a. \#Unos gatos son negros.
ONE.PL cats are black
'A group of cats are black.'
b. Algunos gatos son negros. some.PL cats are black

Some Galician and Catalan examples that illustrate that restriction are given below:
a. \#Unhas formigas son louras.
(Galician)
ONE.PL ants are yellow
'A group of ants are yellow.'
b. Algunhas formigas son louras.
a. \#Unes cloïses són rosses.
ONE.PL clams are yellow 'A group of clams are yellow.'
(Catalan)
b. Algunes cloïses son rosses. some.PL clams are yellow

2. Romance plural-"one" indefinite determiner differs from the plural existential quantifier algunos or from cardinals in that the plural indefinite determiner cannot induce distributive dependencies over some other indefinite in its scope:

$$
\text { Unos estudiantes hicieron una presentación. }
$$

ONE.M.PL students made a presentation

'A group of students made a presentation.'

Unhas raparigas están a abrir unha fiestra.

ONE.F.PL girls are $\mathrm{P}$ open a window

'A group of girls are opening a window.'

\footnotetext{
Unes pageses varem plantar una

ONE.F.PL peasant-women planted a

fageda.

beech-tree wood

'A group of peasant-women planted a beech tree wood.'
} 
Algunas, algunhas, algunes may have scope over an indefinite on their strong reading. In that case, the indefinite description has a presuppositional interpretation equivalent to "some of the NP":

$$
\begin{aligned}
& \text { Algunos estudiantes hicieron una presentación. } \\
& \text { some students made a presentation } \\
& \text { 'Some of the students made a presentation.' }
\end{aligned}
$$

Algunhas raparigas están a abrir unha fiestra. some girls are $\mathrm{P}$ open a window 'Some of the girls are opening a window.'
Algunes pageses varem plantar una fageda.
some.F.PL peasant-women planted a beech wood
'Some of the peasant-women planted a beech wood.'

3. The unos-phrase cannot be interpreted as the range of a binominal distributive construction (Safir and Stowell 1989, Gil 2005), or the antecedent of the distributive numeral sendos ("respective", "one each"):

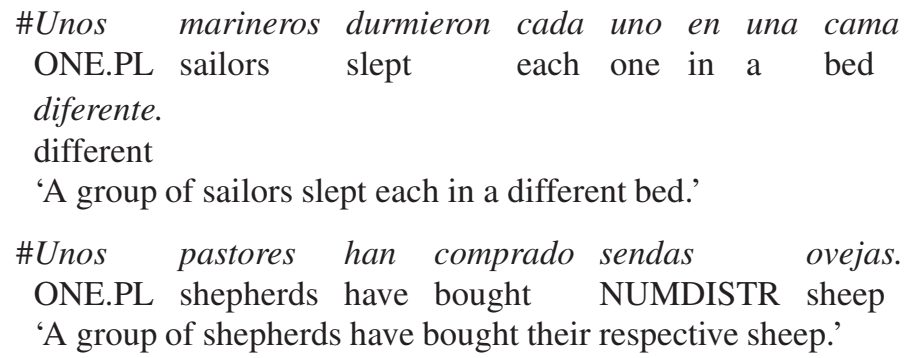

\#Unos pastores han comprado sendas ovejas. ONE.PL shepherds have bought NUMDISTR sheep 'A group of shepherds have bought their respective sheep.'

$$
\begin{array}{llll}
\text { Cuatro pastores han comprado sendas } & \text { ovejas. } \\
\text { four shepherds have bought } & \text { NUMDISTR sheep } \\
\text { 'Four shepherds have bought their respective sheep.' }
\end{array}
$$

4. Unos-DPs cannot be the antecedent of a reflexive or reciprocal pronoun (Gutiérrez Rexach, 130: 35):

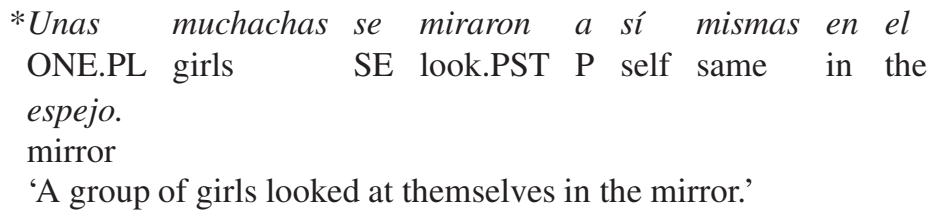

$$
\begin{array}{lllll}
\text { Algunas muchachas se miraron a si mismas. } & \text { si } & \text { me } \\
\text { some girls } & \text { SE look.PST } & \text { P } & \text { self same } \\
\text { 'Some of girls looked at themselves. } & & &
\end{array}
$$


*Unas muchachas se miraron la una a la otra. ONE.PL girls SE look.PST the one.PL $\mathrm{P}$ the other 'A group of girls looked at each other.'

Algunas muchachas se miraron las unas a las otras. some girls SE look.PST the one.PL $\mathrm{P}$ the others 'Some of girls looked at one another.'

For Gutiérrez Rexach, the ungrammaticality of the sentences above is produced by the incompatibility of the group meaning of unos-DPs with a distributive interpretation that reflexive and reciprocal anaphors impose on their plural antecedents. Reflexive and Reciprocal anaphors "denote functions that require access to the atoms of the plural individuals" described by their antecedents (Gutiérrez Rexach 2001: 130).

5. Unos-DPs can be the relevant argument of collective argument-selecting predicates such as rodear "surround", reunirse, "gather", amontonar "pile", in the sentences below:

Unes

ONE.PL ants

formigues envoltaven el pastís.

(Catalan)

'A group of ants surounded the cake.'

Unos estudiantes se reunieron en el pasillo. (Spanish)

ONE.PL students SE gathered in the corridor

'A group of students gathered in the corridor.'

(Gutiérrez Rexach 2001: 120, ex. 17b)

Os mariñeiros
the sailors
peirao.
docks
'A group of sailors gather some boxes on the docks.'

(Galician)

In sum, the interpretation of number of plural indefinite descriptions with unos and with algunos is of a different kind. Unos triggers a group meaning that blocks the access to the internal structure of the plural referent. By contrast, algunos-DPs are ambiguous between a weak and a strong interpretation. On the weak interpretation, algunos-DPs denote the numerosity of a set. On the strong one, they are presuppositional and they may be used in distributive constructions.

How does the unos-phrase obtain its group meaning? Where does that value lie? What does it depend on? Is that group meaning achieved by the same mechanism that contributes a collective meaning on weak algunos-DPs?

Villalta, Laca and Tasmowski, and Gutiérrez Rexach argue that the group meaning of unos-DPs can be attributed to a lexical feature of the indefinite 
determiner. Unos is analyzed as a "group marker" (Villalta) or as a collectivizer determiner (Gutiérrez Rexach 2001: 116). Gutiérrez Rexach proposes that the collective interpretation of unos and algunos is conveyed by different means: As a lexical feature with the group determiner unos and as a discourse property with algunos.

Laca and Tasmowski (1996) apply Heim's (1982) analysis of the English singular indefinite determiner $a$ to the Spanish plural determiner unos. Unos has no quantificational force of its own. Like singular $a$-DPs, the unos-DP contributes a discourse referent whose domain is restricted by the descriptive content of the noun. Laca and Tasmowski argue that the unos-phrase stands for a free group-denoting e-type variable, which acquires the force of any operator with scope over it that may bind it, as for instance, a generic operator, an adverbial quantifier or existential closure. Laca and Tasmowski represent sentence (35) below, in its generic interpretation, as (36).

$$
\begin{array}{llll}
\text { Unos millonarios no viajan en segunda clase. } \\
\text { ONE.PL millionaires not travel in second class }
\end{array}
$$

'Those ones who are millionaires do not travel in second class.'

$$
\begin{aligned}
& \operatorname{GEN}(X)[\text { millionaires }(X)]_{\text {Restriction }} \neg[\text { travel in second class }(X)]_{\text {Scope }} \\
& \text { (Laca and Tasmowski 1996: } 113 \text {, ex. } 6 \mathrm{a}^{\prime} \text { ) }
\end{aligned}
$$

By contrast, algunos-DPs are ambiguous between a quantificational interpretation and a referential one, as was proposed by Fodor and Sag (1982), and by Diesing (1992) for English indefinite descriptions with weak determiners.

Gutiérrez Rexach (2001) builds his account in Dynamic Semantics. He departs from Ladusaw's (1994) psychological reinterpretation of Milsark's weak/ strong distinction, which, in Ladusaw's opinion, arises as a side effect of the kind of judgment performed when uttering the sentence that includes the indefinite DP. ${ }^{8}$ Ladusaw proposes that the cognitive nature of the weak/strong

8. Ladusaw (1994) proposes that the semantic fact captured by Milsark's generalization, expressed in (i), can be viewed as a side effect of the nature of the mental act performed by the speaker:

Two such mental acts that are relevant for the strong/weak distinction are "presentations" and "judgments". A "presentation" consists in the description of an object, which can be an individual ("black cats") or an eventuality ("there are black cats sleeping in the garden"). A "judgment" is a mental act of affirmation or denial, and uses as its base a presentation. Judgments can be formed by a simple or by a complex basis. Thetic judgments have a simple basis. They are expressed, for instance, by sentences used to describe an object (an entity or an eventuality). Categorical judgments are compound. They are made of a presentation of an object, which is brought to our attention, and a predication of affirmation or a denial on that 
distinction can be captured if the ontology of semantic entities includes objects (individuals, eventualities), descriptions of objects, and properties.

Gutiérrez Rexach formalizes the mental acts responsible for the weak/strong meaning of indefinite descriptions as discourse construction steps in Dynamic Semantics. A Discourse Representation Structure consists of referents and atomic conditions on those referents. Referents are introduced in the discourse by determiners. The noun that acts as the restriction, and the predicate that has that nominal expression as argument are represented as conditions on those referents.

Gutiérrez Rexach represents Ladusaw's descriptions (thetic judgments) by an atomic condition (a single basic condition) on the discourse referent, and Ladusaw's properties (categorical judgments) by a duplex condition on the referent. Weak determiners introduce a discourse referent and a single basic condition. Strong determiners introduce a discourse referent and a duplex condition, or else, introduce a new discourse referent and a condition linking it to a previous referent.

Unos and algunos differ in their lexical meaning and in the discourse steps that are compatible with that meaning. Unos introduces a group-denoting referent in the discourse. This referent is associated to an atomic, basic condition. It does not trigger box splitting (Gutiérrez Rexach 2001: 113). That explains why the unos-phrase only appears in thetic judgments (descriptions). Moreover, the referent is subject to a discourse-novelty constraint, which Gutiérrez Rexach formalizes as "a no linking constraint" (p. 113). That restriction accounts for the fact that unos can be used to introduce a referent for the first time but it cannot be referentially linked to a previous introduced entity. The group denotation of the referent "blocks the possibility of the introduction of a duplex condition by distributive expansion" (Gutiérrez Rexach 2001: 151).

Algunos introduces a plural individual (not a group) discourse referent. Weak and strong meanings are derived from discourse processes. The distributive interpretation is obtained when the referent is subject to a duplex and a linking condition; that is, when the sentence expresses a categorical judgment. The group meaning in algunos results when the sentence expresses a thetic judgement (a description) and the referent is subject to a basic condition.

In sum: the group meaning denoted by indefinite expressions with unos and algunos is achieved in a different way: as a lexical feature with unos, and as a discourse property with algunos.

object. The subject of a categorical judgment is "presupposed" in the sense that a condition for making the judgment is that 'the mind of the judger must be directed first to an individual, before the predicate can be connected to it'." (Ladusaw 1994: 222). 


\subsection{Some problems for analyzing unos as a group marker}

The hypothesis that the group denotation of unos-DPs is induced by a lexical feature of the meaning of the determiner encounters the problem that such a group meaning is not constant, but in several contexts, unos-DPs may also have distributive reading:

a. Unos-DPs can be the relevant argument of distributive Stage-level predicates (dormir "sleep", cantar "sing", nacer "be born", caminar "walk"):

$$
\begin{aligned}
& \text { Unos gatos duermen en el jardin. } \\
& \text { ONE.PL cats sleep in the garden } \\
& \text { 'A group of cats sleep in the garden.' }
\end{aligned}
$$

Why is it that the unos-phrase cannot be the relevant argument of Individuallevel predicates, which denote properties of individuals, but it can be the relevant argument of Stage-level predicates that describe an inherently individual activity? Is unos, after all, an ambiguous determiner, like algunos or cardinals?

b. In contrastive topic contexts, unos-DPs seem to cancel the ban on appearing with Individual-level predicates:

$$
\text { Unos gatos son negros, otros son blancos. (Spanish) }
$$
ONE.PL cats are black others are white 'Some cats are black, some others are white.'

Unhas formigas son louras, outras son (Galician) ONE.PL ants are yellow, others are vermellas.

red

'Some ants are yellow, some others are red.'

Unes clö̈ses són rosses, altres son blanques. (Catalan) ONE.PL clams are yellow, others are white 'Some clams are yellow, some others are white.'

c. Futhermore, the unos-phrase, when composed with a specifying relative clause complement, can be interpreted as the range of a binominal distributive construction:

$$
\begin{aligned}
& \text { *Unas llaves abren una puerta cada una. } \\
& \text { ONE.PL keys open a door each one } \\
& \text { 'A bunch of keys open a door each.' }
\end{aligned}
$$




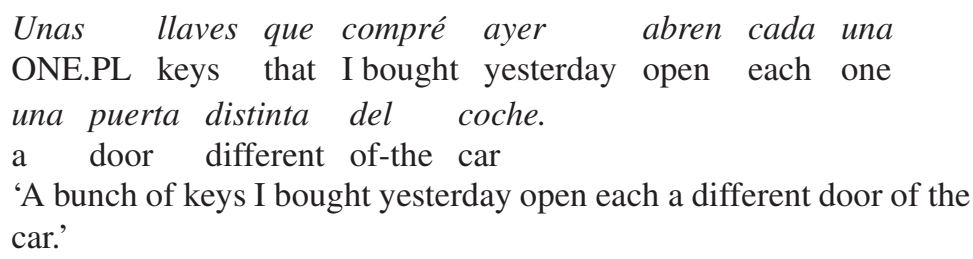

d. When unos is combined with cuantos ("many") or pocos ("few"), as in "unos cuantos NP", it does not necessarily have a group meaning, but it can have either a distributive or a collective interpretation:

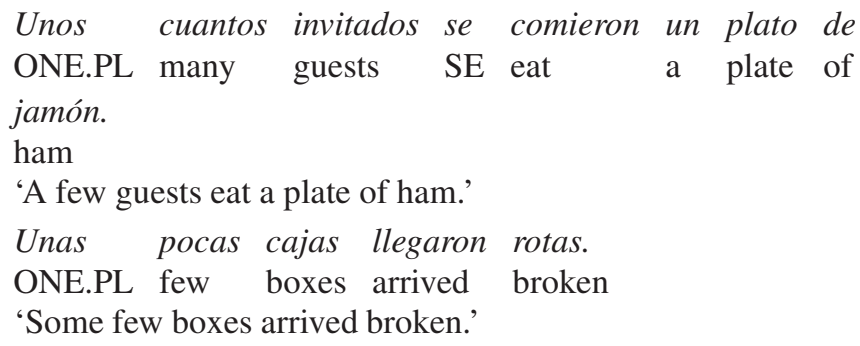

Unas pocas cajas llegaron rotas.

ONE.PL few boxes arrived broken

'Some few boxes arrived broken.'

In sum, the group reading of unos-DPs seems to be unstable, since there are contexts in which the atoms of the group can be accessed. That weakens the empirical basis we could have to analyze unos as a collectivizer.

Perhaps a better option could be to analyze unos as an ambiguous determiner, like algunos and cardinals. On such an analysis, unos would introduce a plural-individual referent, and the group meaning of the unos-phrase would arise as a side effect from its weak interpretation. However, if we adopt such an option and hence, assign the same lexical feature of a plural-individual to the variables introduced by unos and algunos, we will need to think of an alternative explanation to the one presented by Gutiérrez Rexach for the important differences that separate unos-DPs from algunos-DPs in the unmarked contexts illustrated by sentences (16)-(34).

Our option will be to maintain Laca and Tasmowski's, and Gutiérrez Rexach's proposal about the collectivizing nature of unos and to explain the distributive cases as marked ones. We will suggest, though, a modification for Laca and Tasmowski, and Gutiérrez Rexach's analyses that takes into consideration the contribution that unos makes to the semantics of number of the DP in which it appears. We will explain the marked cases, in which unos-DPs may have distributive interpretation, as an effect of the contribution that the speaker's acquaintance with the referent may have on the interpretation of the unos-phrase. We differ from Laca and Tasmowski, and Gutiérrez Rexach in the framework we use in our explanation. We formalize our account in TruthConditional Semantics rather that in Dynamic Semantics. Moreover, we do not 
account for the speaker's knowledge as discourse process steps but we rather represent it as a perspectival notion that may be contextually parameterized.

The remainder of the paper will be structured as follows: In the next section we will study the problem of the number mismatch posed by unos. In Section 4 we will present our analysis of unos as a perspectival choice function. We will depart from Kratzer's version of a Skolem Choice Function. The perspectival argument of the choice function will enable us to account for the role of the speaker's familiarity with the referent in making available the marked distributive reading of the unos-phrase.

\section{The interpretation of number in unos-DPs}

In the section above we saw that assuming that the group denotation of unosDPs is due to a feature encoded in the lexical meaning of the determiner unos is too strong a claim, because of the unstable nature of the group denotation. In this section we propose that the group denotation is an implicit meaning contributed by a covert noun, which is licensed by the indefinite determiner.

What does cause unos to be unstable? We suggest that the key to understanding the variability of the group denotation of unos lies in solving the problem of a number mismatch present in unos-DPs. There appears to be a contradiction in the meaning of number expressed by the lexical content of unos and by its plural morpheme. On the one hand, unos seems to have kept its etymological cardinal meaning of "one" and as such, it denotes a number $n=1$ of entities of the type referred by the noun that it is combined with. But on the other, that lexical meaning is contradicted by the general meaning of the plural morpheme affixed to the determiner.

Unos crucially differs from the plural existential quantifier algunos in the semantic role that the plural morpheme has on it. The plural morphology of algunos denotes a quantity plural, but the plural morpheme of unos stands for an uninterpretable feature. The semantic contribution of unos to the quantity denotation of unos-DPs is derived from its etymological meaning of unity that unos encodes in its root.

How does unos saturate its lexical meaning of "unity"? To do so, unos needs to be combined, like an ordinary cardinal word would do, with an atomdenoting nominal expression. But the plural noun in the unos-phrase does not provide such a domain. We suggest that unos is not directly composed with the plural noun that follows it, but it is composed with a covert noun whose domain of interpretation is a class of group atoms. Unos is not, thus, a direct semantic determiner of the plural noun, but of that group-denoting covert noun.

Unos differs in that interpretation from algunos, which directly quantifies over the atomic entities of a domain described by the plural noun. Thus, in 
contrast to unos gatos ("ONE.PL cats"), algunos gatos ("some.PL cats") does not have the denotation "some group of cats", but has a meaning that could be paraphrased as "some atoms of the class cat". That is, it denotes a plural individual that may have either a distributive or a collective interpretation. ${ }^{9}$

We propose the following syntactic structure for "unos N.PL", which aims at representing the selectional properties of the plural-"one" indefinite determiner:

$$
\text { [DPunos[NP } e . G R O U P[\ldots[\mathrm{NPN} . \mathrm{PL}]]]]
$$

Unos is a singleton indefinite. It lexically expresses the numerosity $n=1$ of atoms of the kind referred to by a covert group-denoting sortal noun "e.GROUP", and licenses it. Applying a Heim-style analysis for indefinite descriptions to the syntactic structure above, we could give the following denotation for "unos $e$.GROUP":

$$
[[\operatorname{unos} e \cdot \mathrm{GROUP}]]^{\mathrm{g}}=\lambda x \in g\left(\mathrm{D}_{e}\right) \cdot \operatorname{ATOM}(x) \&\{x\}=|1| \& \operatorname{GROUP}(x)
$$

The indefinite determiner introduces a variable $x$ whose domain D is restricted to the set of entities that have the property of being an abstract unit "atom", and whose cardinality is " 1 ". The implicit group term "e.GROUP" stands for a sortal group-property. It restricts the domain of the variable to the set of atomic entities intensionally defined by having a group-property.

In what way is the meaning of a group expression different from the meaning of a plural individual one? Group-denoting expressions differ from plural individual-denoting ones on the linguistic level at which the operation that forms them applies. A plural individual-denoting expression is obtained by plural morphology or by NP-conjunction, while a group-denoting one is formed in the lexicon.

For the semantics of plural individuals, we assume Link's (1983) algebraic account of plurality. A plural individual-referring expression denotes a domain of a structured collection of atomic entities that is obtained by the closure of

9. Luisa Martí (2006) gives a compositional account that relates the denotation of algunos, a generalized quantifier of type $\langle\langle\mathrm{e}, \mathrm{t}\rangle \mathrm{t}\rangle$, to that of the denotation of unos. In her opinion, algis the segment that contributes the context-sensitivity of algunos NPs, which is absent in unos-phrases. She proposes the following denotation for that segment, where $\mathrm{C}$ stands for a contextual variable:

(i) $\quad[$ alg- $]=\lambda \mathrm{C}_{\langle\mathrm{e}, \mathrm{t}\rangle} \cdot \lambda g_{\langle\mathrm{e}, \mathrm{t}\rangle} \cdot \lambda f_{\langle\mathrm{e}, \mathrm{t}\rangle} \cdot \exists x \mathrm{C}(x)=1 \& g(x)=1 \& f(x)=1$

(i) expresses that alg-takes three arguments: a contextually relevant set, C, the set contributed by the noun $g$, and the set contributed by the predicate $f$. She proposes a compositional semantics for algunos chicos as:

$\llbracket$ algunos chicos $\rrbracket=\lambda_{\langle\mathrm{e}, \mathrm{t}\rangle} \cdot \exists x \mathrm{C}(x)=1 \& x$ is a plural boy individual $\& f(x)$ 
the nominal predicate under sum formation. A plural individual is built from atomic ones by the star* operator, which takes any two atoms and returns an individual sum. It may also be built from previously formed sums. Sums are, thus, cumulative. For instance, the plural individual-denoting nominal predicate "cats" results from applying the *-operator to the atom-denoting nominal predicate "cat", or to plural individuals already formed:

$$
[[\text { cats }]]=\lambda \mathrm{P}_{\langle\mathrm{e}, \mathrm{t}\rangle} \cdot \lambda x_{e} \cdot{ }^{*} \mathrm{P}(x)([[\mathbf{c a t}]])=\lambda x * \operatorname{cat}(x)
$$

A plural individual formed by sum closure has a transparent part structure because the primitive atoms used to build the sum are always available from the variable.

By contrast, a group-denoting noun, such as "committee", "team", "army", "tribe", "group", "set", "dozen", "couple" or "family", describes a plural individual that has been already formed in the lexicon as an atom, and has, hence, an opaque part structure. ${ }^{10}$ The individuals of the plurality denoted by an intransitive group term cannot be directly accessed, for instance, by verbal plural agreement, because they are expressed by lexical features of the groupdenoting noun:

$$
\begin{aligned}
& \text { *El ejército chino están luchando entre si. (Spanish) } \\
& \text { the army chinese are fighting among themselves } \\
& \text { 'The Chinese army are fighting among themselves.' } \\
& \text { *O exercito chinés están a loitar entre eles. (Galician) } \\
& \text { the army chinese are fighting among themselves } \\
& \text { *L'esercito cinese stanno lottando tra di loro. (Italian) } \\
& \text { the_army chinese are fighting among P themselves }
\end{aligned}
$$

However, it is possible to refer to the internal parts of a transitive groupdenoting term if it is used as a transitive noun. ${ }^{11}$ The following Spanish examples illustrate that possibility:

10. For Barker (1992), group terms are the only real group-denoting expressions. Conjoined NPs or plurals denote plural individuals and not groups.

11. Brucart (1997: 172) observes that the possibility of plural agreement depends crucially on the presence of the plural noun that describes the members' class: 'La posibilidad de la concordancia ad sensum depende de la existencia de una coda en plural:

(i) a. La mayoría de los estudiantes piensan aprobar the majority of the students think pass_the_exam

b. *La mayor parte de la gente ven la televisión" the major part of the people watch the television (Brucart 1997: 172-173, ex. 28a, 28b) 


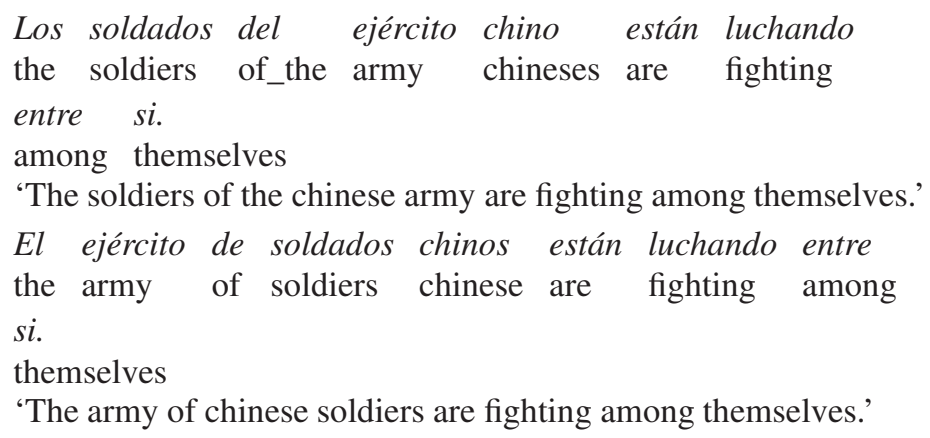

The sentences above have a transitive group-denoting subject, "army of chinese soldiers", and in both sentences, the internal parts are accessible, although only in the first sentence the members-denoting plural noun is the head of the phrase. In (51) the members-denoting plural noun "soldiers" heads the complex NP, and the verb agrees ad formam with it (Corbett 2003). In (52) the members-denoting noun complements the group-denoting head "army of chinese soldiers", and the verbs agrees ad sensum with the members-denoting complement. ${ }^{12}$

The compositional meaning of the relation between a group and its parts has been represented as function application. It has been proposed that a group is related to its members through a constitute relation (Link 1984, Barker 1992, Landman 2004, Winter 2001). ${ }^{13}$

Baker (1992) gives a model-theoretic account for the semantics of intransitive and transitive group terms. The Model is a tuple $\langle E,+,[[], f$.$\rangle . The set E$ is the domain of discourse, + is the join operator, [.].] is the interpretation function, which maps expressions onto their denotations, and $f$ is the membership function, which maps $E$ into $E$ so that $f(a+b)=f(a)+f(b)(f$ is an automorphism in $E$ ). Barker represents the Membership Function, as it is expressed by the relational use of the English preposition "of" in a transitive group-denoting NP like "committee of (the) men", as follows (Barker 1992: 75, ex. 15b):

12. Ad sensum agreement is also used in Galician, Catalan or Italian:

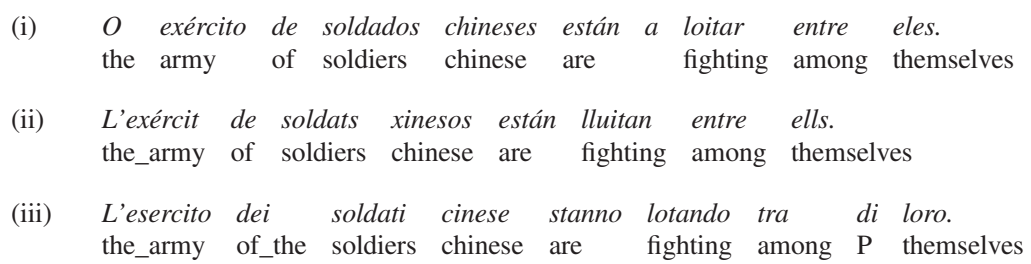

13. The constitute function associates an entity with the portions of matter that make it up (Barker 1992: 6; Link 1998) 


$$
\llbracket \mathbf{o f} \rrbracket=\lambda y \cdot \lambda \mathrm{Q}_{\langle\mathrm{e}, \mathrm{t}\rangle} \cdot \lambda x\left[\mathrm{Q}(x) \& f_{x}(y) \leq * \mathrm{P}(z)\right]
$$

The formula above expresses that an entity $x$ will be in the extension of a groupdenoting predicate $\mathrm{Q}$ just in case $\mathrm{Q}(x)=1$ and each of the members of $x, f(y)$, is an element in the extension of the predicate $* \mathrm{P}$.

Let us go back to the group interpretation of unos-DPs and their unstable nature. We said that unos is not the semantic determiner of the plural noun that follows it. The plural noun describes the member's class of a covert group term selected by unos. We now suggest that the group meaning denoted by the unosphrase is composed by the same rules used to calculate the meaning of group terms.

Before we proposed for unos-DPs the syntactic structure in (45), repeated below as (54), in which unos selects a covert group-denoting noun:

$$
\text { [DP unos [NP } e \text {.GROUP [ } \ldots \text { [NPN.PL]]]] }
$$

The denotation we gave for "unos $e$ :GROUP" was:

$$
[[\mathbf{u n o s} e \cdot \mathrm{GROUP}]]^{\mathrm{g}}=\lambda x \in g\left(\mathrm{D}_{\mathrm{e}}\right) \cdot \operatorname{ATOM}(x) \&\{x\}=|1| \& \operatorname{GROUP}(x)
$$

Unos stands for a variable $x$ in the domain of a singleton set $\{x\}$ whose single member has the atom-property. The domain of the variable is restricted by the covert group term.

Now we will compose the meaning of "unos $e$.GROUP" with the denotation of the plural noun in the unos-phrase, which describes the members' domain. As it is the case with lexically expressed group terms, we suggest that the relation between the members-denoting plural noun in the unos-phrase and the empty group-denoting term is mediated by a constitute function. We will base our account on Barker's Model for groups referred above.

We propose that the group denoted by unos-DPs is formed by a groupConstitute Function $\Gamma$, which maps a sum of individuals $* \mathrm{P}$ onto a group-atom $\mathrm{G}(x)$ whose members are $y:{ }^{14}$

$$
\Gamma(\lambda y \cdot * \mathrm{P}(y))=\lambda x \cdot \operatorname{GROUP}(x)
$$

We might, then, define the internal structure of a group atom $x$, as a property of its members, by means of a Membership Function $\mu$ :

14. Landman (2004) proposes that the formation of a group is undertaken by a group formation operator, which he represents as "^": The group-formation operation "shifts the semantically plural interpretation of a noun phrase like the boys as $\sigma(* \mathrm{BOY})$, the sum of the boys, to a corresponding sermantically singular interpretation, as a group atom: the boys regarded as a singular entity in its own right, i.e., with its part-of structure of singular boys ... ignored.” p. 239)

(i) $\quad \uparrow \sigma(* \mathrm{BOY})=\mathrm{G}$ 


$$
\operatorname{GROUP}_{\mathrm{x}}=\left\{y: \mu_{\mathrm{x}}(y) \& y \in \mathrm{P}\right\}
$$

By (57) we express that $y$ is a member of the set Group $x$ and $y$ is an element in the set described by P.

The group constitute function $\Gamma$ could be represented as a relational component of the covert group term, which becomes, then, a function from a sumdenoting $\langle\mathrm{e}, \mathrm{t}\rangle$-predicate onto a group-denoting nominal predicate:

$$
\begin{aligned}
& {[[e . \mathrm{GROUP}]]=\Gamma\left(\lambda y \cdot * \mathrm{P}(y) \bullet \lambda x . \mathrm{G}(x)=1 \text { iff } x \text { is a group } \& \forall z . \mu_{x}(z) \rightarrow\right.} \\
& z \leq y)
\end{aligned}
$$

In the representation above, the relation "being a member of" that holds for the individual that has the property $\mathrm{P}$, is expressed by means of a membership function $\mu . \mu_{\mathrm{x}}(z)$ expresses that the element $z$ is a member of the group $x$.

As an illustration, we apply below the group-constitute function $\Gamma$ to the plural noun gatos, "cats" to compose the group meaning in unos gatos, " $e$.GROUP gatos":

$$
\begin{aligned}
{[[e . G R O U P \text { gatos }]] } & =\llbracket[e . G R O U P]]([\text { gatos }]) \\
& =\lambda \mathrm{P}_{\langle\mathrm{e}, \mathrm{t}\rangle} \cdot \Gamma(\lambda y \cdot * \mathrm{P}(y) \cdot \lambda \mathrm{x} . \mathrm{G}(x))([[\text { gatos }]]) \\
& =\Gamma(\lambda y . * \operatorname{gato}(y) \cdot \lambda \mathrm{x} . \mathrm{G}(x))
\end{aligned}
$$

Using the semantics of group terms to compose the group meaning of unosDPs enables us to give a principled explanation for the allegedly unexpected distributive reading of the unos-phrase. We can access the internal structure of the group without the group losing its group property because, by means of the constitute function, we can always keep track of the relation.

We propose that the distributive interpretation of unos-DPs is not directly obtained from the members' denoting plural noun, but it is indirectly derived from the inverse of the constitute function:

$$
\begin{aligned}
\llbracket[e . \mathrm{GROUP} * \mathrm{P} \rrbracket & =\Gamma^{-1}(\lambda x . \mathrm{G}(x) \bullet \lambda y \cdot * \mathrm{P}(y) \\
& \left.=1 \text { iff } y \text { is a sum } \& \forall z . \mu_{x}(z) \rightarrow z \leq y\right)
\end{aligned}
$$

Since the variable $y$ denotes now a sum individual the members are accesibble. The availability of the distributive reading of unos-DPs is not, hence, a contradiction to the group analysis, but is an interpretation that follows from the transitive nature of the covert group predicate. That is, the instability of the group denoted by unos-DPs is, in fact, a general property of group denoting NPs headed by a transitive group term.

The covert group term selected by unos just contributes a sortal concept of group. The members-denoting plural noun can further specify the content of the group. The particular lexical meaning of such a covert noun may be 
easily recovered in the case of pluralia tantum nouns that denote a dual entity ("boots", "gloves", "binoculars", recién casados "just married couple"): ${ }^{15}$

unas botas

ONE.F.PL boots

'a pair of boots'

$$
\begin{aligned}
& \text { un par de botas } \\
& \text { one pair of boots }
\end{aligned}
$$

The lexical contribution of the noun "pair" to the meaning of the expression "a pair of boots" copies the dual-number meaning already expressed as a lexical feature by the pluralized noun "boots". So eliding the noun "pair" has no semantic cost as far as the dual nature of the group entity is concerned. Both constructions un par de botas ("a pair of boots") and unas botas("one.PL boots") could be used with a similar meaning.

In sum, we have proposed that the indefinite description with plural-"one" includes an implicit group-denoting transitive noun, which is licensed by the indefinite determiner:

\section{ONE.PL e.GROUP N.PL}

The implicit group term includes as a relational feature of its sortal denotation a group-constitute function $\Gamma$, which applies to an i-sum denoting nominal predicate and returns a group:

$$
\begin{aligned}
{[[e . \mathrm{GROUP}]] } & =\Gamma(\lambda y . * \mathrm{P}(y) \bullet \lambda x . \mathrm{G}(x) \\
& \left.=1 \text { iff } x \text { is a group } \& \forall z \cdot \mu_{x}(z) \rightarrow z \leq y\right)
\end{aligned}
$$

The internal structure of a group atom $x$ is defined as a property of its members by means of a Membership Function $\mu$

$$
\operatorname{GROUP}_{\mathrm{x}}=\left\{y: \mu_{\mathrm{x}}(y) \& y \in \mathrm{P}\right\}
$$

15. The plural use of the indefinite determiner "one" could have started in constructions in which a group-denoting pluralia tantum expression is composed as the subject of a distributive predicate that has ad sensum agreement:

(i)

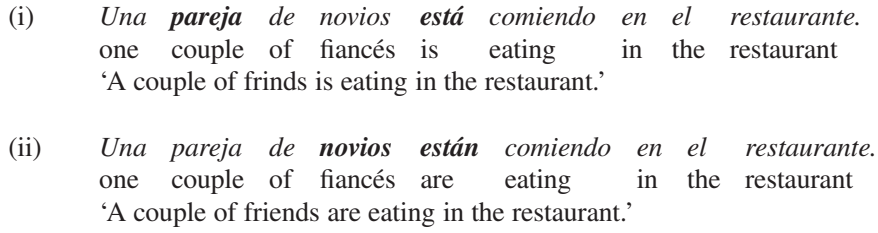


The inverse of the constitute function $\Gamma^{-1}$ enables us to access the internal structure of the group, which we need to compose the distributive interpretation of unos-DPs. $\Gamma^{-1}$ maps a group onto its constituent members:

$$
\begin{aligned}
{[[e . \mathrm{GROUP} * \mathrm{P}]] } & =\Gamma^{-1}(\lambda x . \mathrm{G}(x) \cdot \lambda y . * \mathrm{P}(y) \\
& \left.=1 \text { iff } y \text { is a sum } \& \forall z . \mu_{x}(z) \rightarrow z \leq y\right)
\end{aligned}
$$

The group meaning in unos-DPs is not drawn from a unique source. It is obtained, as a sortal category, from the selectional properties of unos, which licenses the covert group term. It is also obtained, as an inferred content, from the lexical meaning of the members-denoting plural noun. The more we rely on the selectional properties of the indefinite determiner, the less precise is the group meaning. In that case, the access to the parts may depend on our familiarity with the group. And the parts become increasingly accessible as our perception of the group object is more vivid.

It seems, in sum, that the nature of the knowledge needed to process the group meaning denoted by unos-DPs is heterogeneous. It includes: (a) The selectional properties of the determiner. (b) The ontological knowledge, which has to be inferred from the lexical meaning of the members-denoting plural noun. (c) The speaker's familiarity with the group. Such diverse knowledge is not necessarily obtained from the discourse. Therefore, Gutiérrez Rexach's Dynamic Semantics account does not seem to be able to explain all the semantic operations needed to calculate the group meaning of unos-DPs.

We suggest that an economical way to deal with the role that the inferred knowledge and the speaker's familiarity with the referent have on the interpretation of the group denoted by unos-DPs is to analyze the indefinite plural"one" determiner as a perspectival choice function. That analysis will enable us to assemble the last missing piece needed to solve the puzzle of the group interpretation of plural-"one" DPs: the role of the speaker's beliefs. In the next section we will propose such an analysis. We will base our account in Kratzer's version of a Skolem Choice Function (1998).

\section{An epistemic proposal for the group denotation of unos-DPs. Unos is a perspectival choice function}

In this section we will briefly introduce Kratzer's (1998) concept of perspectival choice function and then we will apply it to explain the variability of the group meaning denoted by unos-DPs. We propose that unos denotes a choice function variable that takes a group-denoting predicate and returns a unique group denoting entity, whose selection may be contextually parameterized to the holder of a perspective. 
A choice function is a partial function that takes as its argument a nominal predicate that denotes a set of individuals among which it selects a unique element of the set. Hence, a choice function is of type $\langle\langle e, t\rangle, e\rangle$. Reinhart (1997) proposed that certain indefinite determiners are pronominal elements that may introduce variables over choice functions. Take, for instance, the sentence

\section{A tiger is climbing the tree.}

The sentence above can be interpreted as an existential statement about a choice function variable $f$. The choice function variable takes the predicate tiger and returns an individual, a tiger, which denotes 'the unique tiger' that $f$ selects from the domain of tigers. That is, a tiger is interpreted as:

$$
f_{\langle\langle\mathrm{e}, \mathrm{t}\rangle, \mathrm{e}\rangle}(\lambda x \cdot \operatorname{tiger}(x))
$$

where $f$ is a variable ranging over choice functions, and the individual selected by the choice function is in the extension of the predicate is climbing the tree.

A Perspectival Choice Function parameterizes the value of the choice function variable to the holder of a viewpoint. One technical way to do that is by adding an argument to the choice function variable that stands for the perspective:

$$
f_{\langle\langle\mathrm{e}, \mathrm{t}\rangle, \mathrm{e}\rangle}(y, \lambda x \cdot \operatorname{tiger}(x))
$$

The variable $y$ may fix its value to the holder of a perspective, who determines the particular individual chosen by the choice function.

Perspectival choice functions were introduced by Kratzer (1998), who applied a Skolem-type Choice Function to represent the dependent readings that indefinites may obtain in sentences with quantifiers, like the sentence below:

$$
\begin{aligned}
& \text { Every professor rewarded every student who read a book she had rec- } \\
& \text { ommended. }
\end{aligned}
$$

(Kratzer 1982: 5, Ex. 5a)

In the intermediate scope interpretation of the indefinite, the actual book picked by the choice function in (70) may be determined by the QP every professor. For each one of the professors the function selects a different book. To represent that dependence of the indefinite denotation on the QP, the choice function is skolemized and an implicit argument variable is added to the function. That implicit argument is bound by the every-phrase:

$$
\forall x: x \text { is professor ( } x \text { rewarded every student who read } f(x, \text { book }))
$$

Skolem Choice Functions also succeed in capturing contextual saliency, which may be induced by the overt reference to the first person, as it is illustrated by the sentence below: 
Every professor rewarded every student who read a book I had recommended.

(Kratzer 1998: 5, ex. 5b)

To represent the specifying effect the first person pronoun has on the indefinite determiner interpretation we parameterize the implicit argument of the choice function to the speaker:

$\forall x: x$ is professor ( $x$ rewarded every student who read $f$ (speaker, book))

In sum, by skolemizing the choice function variable that represents the indefinite determiner, we are able to express quantifier dependencies and the role of contextual salience on the interpretation of indefinites.

We will now apply Kratzer's style of perspectival choice function analysis to calculate the meaning of unos. Let us consider the following sentence:

$$
\begin{aligned}
& \text { Unos monos gelada están saltando de árbol en } \\
& \text { ONE.PL baboons gelada are climbing from tree to } \\
& \text { árbol. } \\
& \text { tree } \\
& \text { 'A group of gelada baboons are climbing from tree to tree.' }
\end{aligned}
$$

In the sentence above, unos monos gelada may have both a specific and an unspecific interpretation. When specific, the indefinite describes a group the speaker is acquainted with. Suppose, for instance, that the speaker, who is a naturalist doing research on gelada baboons' behavior, has witnessed the event described by sentence (74), and that she has been able to identify the group of gelada baboons, which perhaps, is made of members belonging to the same family the speaker has been following for some time.

Unos is a place holder for a singleton-denoting variable " $x \in g\left(\mathrm{D}_{e}\right) \cdot \operatorname{ATOM}(x)$ $\&\{x\}=|1|$ ". On a specific reading of the sort of the one described above, the value assigned to the free singleton variable depends on the speaker's acquaintance with the referent. The perspectival choice function analysis enables us to account for such dependence. In the form below, we represent unos as a perspectival choice function $f$ parameterized to the speaker. Unos is applied to the group-denoting " $\Gamma(\lambda y$. *gelada baboon $(y) \bullet \lambda x . \mathrm{G}(x))$ " and yields a unique group of gelada baboons the speaker believes will make the sentence true:

$$
\begin{aligned}
& f^{\text {speaker }}\left(\Gamma \left(\lambda y . * \text { gelada baboon }(y) \bullet \lambda x . \mathrm{G}(x)=1 \text { iff } x \text { is a group } \& \forall z . \mu_{x}(z)\right.\right. \\
& \rightarrow z \leq y) \text { are climbing from tree to tree. }
\end{aligned}
$$

The above representation says that unos is a choice function of type $\langle\langle\mathrm{e}, \mathrm{t}\rangle, \mathrm{e}\rangle$, which takes a nominal predicate denoting a non-empty set of groups of gelada 
baboons out of which the speaker picks a unique group member of the set. That is, " $f$ speaker $(\Gamma(\lambda y . *$ gelada baboon $(y) \bullet \lambda x . \mathrm{G}(x)))$ " expresses that the property of being a group of gelada baboons is instantiated by the unique plural individual chosen by the perspectival choice function unos, parameterized to the speaker.

When the speaker uses unos monos gelada to describe a specific group she is acquainted with, her familiarity with the group enables her to refer, if she wishes so, to its members. We represent the access to the members by the inverse of the group-constitute function:

$$
\begin{aligned}
& f\left(z^{\text {speaker }}, \Gamma^{-1}(\lambda x . \mathrm{G}(x) \cdot \lambda y . * \text { gelada baboon }(y)=1 \text { iff } y \text { is a sum \& }\right. \\
& \left.\left.\forall z . \mu_{x}(z) \rightarrow z \leq y\right)\right) \text { are climbing from tree to tree. }
\end{aligned}
$$

How is the non-specific reading of the unos-phrase composed? We suggest that on the unspecific interpretation, the choice function variable remains free. We do not have enough information to identify the particular group that makes the sentence true in the actual world. Due to a lack of identifying information, Skolemization of the choice function does not seem to be necessary:

$$
f(\Gamma(\lambda y . * \operatorname{gelada} \operatorname{baboon}(y) \bullet \lambda x . \mathrm{G}(x))) \text { are climbing from tree to tree. }
$$

In the representation above, the underspecification of the perspectival argument, which we leave, thus, unexpressed, matches the lack of knowledge about the referent of a holder of a perspective. (77) expresses that the group described by unos monos gelada is not familiar to the speaker. The speaker cannot refer to the members of the group because her knowledge of the referent is imprecise.

On the unspecific interpretation, the plural indefinite description with unos denotes a fuzzy group. We cannot access the atoms of the group because they are not well identified, for whatever reason that may be. The speaker is vague when referring to the group, and we perceive it as a blurred bunch of entities involved in a common event. We do not know the quantity of entities that make the group, and we cannot identify the individual members. We will call that fuzzy group a cluster. ${ }^{16}$

In sum, in this section we have seen that using a perspectival choice function to represent the denotation of unos enables us to give a principled account of the role that the speaker's beliefs have on the interpretation of unos-DPs.

16. Alonso Ovalle and Menéndez Benito (2002) propose for Spanish singular determiner algun ("some") a free-choice epistemic account. They suggest that algun induces a free-choice epistemic effect. The epistemic effect marks the speaker's lack of knowledge. Algun widens its domain to include epistemic alternatives. By using algun-N, the speaker signals that for each $x$ in the domain there has to be an epistemic alternative $\mathrm{w}$ such that the proposition containing $x$ is in $w$. The epistemic effect of algun-DPs comes about as a result of the interaction of epistemic modality with the domain widening that algun induces. 


\section{Helena Lopez Palma}

In Section 5 we will see some instances in which familiarity with the referent contributes to making the distributive reading of the group denoted by the unos-phrase more available. We will represent that knowledge by means of the perspectival implicit argument of the choice function. But first, we will review some differences between fuzzy-group unos-DPs and bare plural nouns.

\subsection{Fuzzy group unos-DPs versus bare plurals}

Spanish bare plurals differ from unspecific unos-DPs in their semantic type and in the operation by which they compose with the main predicate. Bare plurals are interpreted as properties (Laca 1996, McNally 1995). They differ in their distribution from unos-DPs. Bare plurals, but not unos-DPs, are interpreted with narrowest scope. For instance, bare plurals are in the scope of negation or intensional verbs (creer, "believe", buscar "seek"):

$$
\begin{aligned}
& \text { a. A la reunión no asistieron profesores. } \\
& \text { to the meeting not attend professors } \\
& \text { 'Professors did not attend the meeting.' }
\end{aligned}
$$

b. A la reunión no asistieron unos profesores.

to the meeting not attend ONE.PL professors

'A group of professors did not attend the meeting.'

c. A la reunión no asistieron algunos profesores.

to the meeting not attend some professors

'Some professors did not attend the meeting.'

(Laca 1996: 253, Ex. 35)

a. María cree que Sara adiestra perros.

Maria believes that Sara trains dogs

'Maria believes that Sara trains dogs.'

b. María cree que Sara adiestra a unos perros.

Maria believes that Sara trains P ONE.PL dogs

'Maria believes that Sara trains a group of dogs.'

(Laca 1996: 254)

Unos-DP may be used to refer to some specific dogs Maria is acquainted with in the de re interpretation.

a. María está buscando libros que *describEN

Maria is looking for books that describe.IND

Galicia.

Galicia 


\subsection{The interpretation of tense}

Stage-level verbs like dormir ("sleep"), cantar ("sing"), nacer ("be born"), morir ("die") are distributive verbs that select an atomic individual denoting subject. However, that selectional restriction does not prevent those verbs from combining with the group denoting indefinite description with unos:

$$
\begin{array}{llll}
\text { Unos } & \text { gatos duermen } & \text { en el jardin. } \\
\text { ONE.PL } & \text { cats sleep } & \text { in the garden }
\end{array}
$$

In Section 2.1 we assumed that, in those cases, the lexical meaning of the verb forces a distributive reading in the unos-phrase. However, it would be wrong to draw such a conclusion, because the distributive reading is not the only interpretation the indefinite may have in sentence (37). The unos-phrase has also a fuzzy group reading in the habitual interpretation of the present tense. We argue that the fuzzy group reading is the default interpretation of unos-DPs in those sentences. The distributive meaning is a marked interpretation we obtain when the tense of the verb is deictically anchored. Let us consider first the habitual reading of sentence (37).

$$
\begin{array}{lllll}
\text { Unos } & \text { gatos duermen cada día en el jardín. } \\
\text { ONE.PL cats sleep } & \text { every day in the garden }
\end{array}
$$

Even though the verb lexically selects an individual-denoting subject, the sentence seems to express a single event performed by a group of cats, which is existentially quantified, rather than a plurality of events. Such an event is then interpreted inside of the scope of the habitual adverbial quantifier expression cada día (every day), and that adverbial quantifier is precisely the element that triggers plurality in the event. Thus, the sentence could be paraphrased as "For every day, there is an event of sleeping a group of cats in the garden."

(85) For every day $\exists$ e[sleep ONE.PL $e$.GROUP (of) cats in the garden (e)]

Suppose we include in the sentence an indefinite description that could function as a distributive share (en un rincón, 'in a part'):

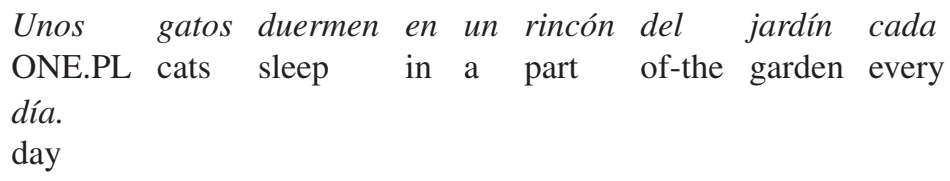

In such case, the indefinite in the locative phrase en un rincón establishes a distributive relation with the habitual adverbial quantifier, and it does not take unos gatos as the range for distribution. Here also, unos gatos has a group interpretation, and the sentence could be paraphrased as 'The event of sleeping 
a group of cats in the garden occurs every day in a different part of the garden.' Therefore, in its habitual reading, the event of sleeping a group of cats described in sentence (37) has a meaning that could be represented as:

$$
\operatorname{sleep} \operatorname{unos}(\Gamma(\lambda y \text {.*at }(y) \bullet \lambda x \text {. G }(x)))
$$

Habitual reading. Fuzzy group interpretation

In this case, sleeping is seen as a single collective event performed by a group of cats. Let us now consider the interpretation of sentence (37) anchored to the time of utterance, as it is unambiguouly expressed by the continuous tense:

$$
\begin{array}{lllll}
\text { Unos } & \text { gatos están durmiendo en el jardin. } \\
\text { ONE.PL cats are sleeping in the garden. }
\end{array}
$$

In such a deictic interpretation of the time of the sleeping event, the unos-phrase can be used to describe the range of a distributive relation:

$$
\begin{aligned}
& \text { Unos gatos están durmiendo en un rincón del } \\
& \text { ONE.PL cats are sleeping in a part of-the } \\
& \text { jardí cada uno. } \\
& \text { garden each one }
\end{aligned}
$$

The sentence above describes a plurality of sleeping events performed by the individual cats of a group. Such a meaning can be formalized as (90), where the possibility of accessing the atoms of the group is represented by the inverse of the group-constitute function:

$$
\begin{aligned}
& * \text { sleep unos }\left(x, \Gamma^{-1}\left(\lambda z . \mathrm{G}(z) \bullet \lambda y .{ }^{*} \operatorname{cat}(y)\right)\right) \\
& \text { Actual reading. Distributive group interpretation }
\end{aligned}
$$

How can we explain the difference in the interpretation of unos-DPs in the sentence with the habitual and with the actual reading of the present tense? How do we obtain the fuzzy group reading of the unos-phrase in the habitual event denoting sentence and the distributive meaning in the actual event denoting one? The distributive verb "sleep" selects an atomic individual subject, but it is not an anti-collective predicate. Therefore, the sentence may denote an instantiation of a single event of a group of individuals that are all gathered at the same place, performing the same action at the same time. As "unos $(\Gamma(\lambda y$. *at $(y) \bullet$ $\lambda x$. $\mathrm{G}(x))$ )" establishes a group unit, the collective meaning is the one obtained in the unmarked interpretation, when there is no aspect of the context that fixes the perspective. But if we anchor the time of the event to the time of the speech act, the implicit argument of the choice function is identified by the context and the individual atoms of the group denoted by the unos-phrase may be accessed through the inversion of the membership function: 


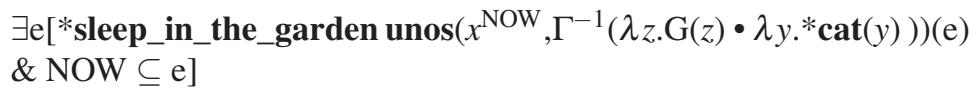

Thus, the individual reading we observed in (37) is not a property of the lexical verb itself but of the deictic tense.

\subsection{Identifyng modifiers}

The co-occurrence of the unos-DPs with identifying modifiers favors the distributive interpretation of the group. Thus, when the unos-phrase is combined with some adjectives, or relative clauses with the verb in indicative, that contribute to making the indefinite group specific, the indefinite group may have a distributive reading. Some of those adjectives include prenominal ciertos ('certain'), determinados ('determined'), conocidos ('known'), famosos ('famous'), etc. Bosque (2001) studies the specifying effect some of those kinds of adjectives have on indefinites. We illustrate that property of identifying modifiers in the sentences below:

Unos conocidos lingüistas defendían posturas

ONE.PL known linguists defended points_of_view

distintas.

different

'A group of well known linguists defended different positions.'

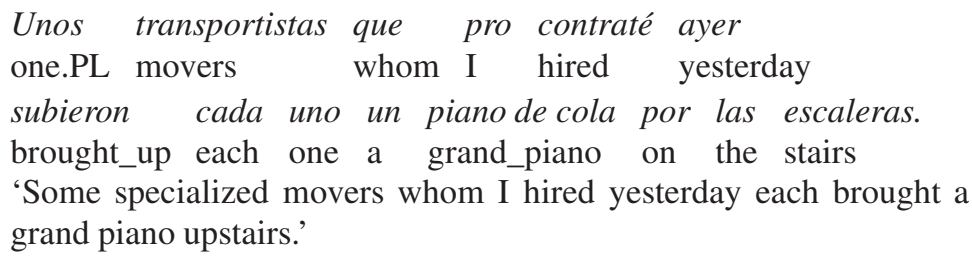

The adjective conocidos ("known") delimits the range of possible choices to a group the speaker is familiar with. The implicit argument of the perspectival choice function is, then, parameterized to the speaker, who may access the atoms of the group:

$$
\begin{aligned}
& \text { unos }^{\text {speaker }}\left(\Gamma^{-1}(\lambda x \mathrm{G}(x) \bullet \lambda y \text {.well_known_*linguist }(y))\right) \text { defended dif- } \\
& \text { ferent points of view. }
\end{aligned}
$$

Conocidos and ciertos differ in the contribution they make to identifying the referent chosen by the choice function. With ciertos, only the speaker is acquainted with the referent, but with conocidos the familiarity with the group is generalized to people other than the speaker. 


\subsection{The structure of the information}

The structure of the information conveyed by the sentence has an effect on the interpretation of indefinites. Villalta (1994), Laca and Tasmowski (1996) and Gutiérrez Rexach (2001) noted that when the unos-phrase is contrasted in the discourse with otros ("others"), the plural indefinite description might function as the subject of an individual level predicate:

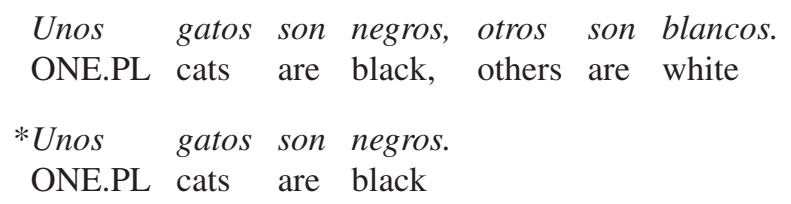

Why is sentence (34) acceptable while (12) is not? Such difference in acceptability judgments that puzzled us in Section 2 seems, then, to be related to the structure of the information, and not to the lexical meaning of unos. For sentence (12) to be acceptable, we need to contrast the group denoted by the unos-phrase with some other group(s) belonging to the same class. That is, unos-DPs may be the relevant argument of an Individual-level predicate, if it is interpreted as a contrastive topic and not just as a topic: ${ }^{17}$

[Unos gatos $\left.{ }_{\mathrm{CT}}\right]$ son negros, [otros $\left.x_{\mathrm{CT}}\right]$ son blancos.

A contrastive topic presupposes a class of alternatives that the speaker wants to talk about (Krifka 1999). In the sentence above, the plural noun "cats" is perceived as a contrast class (Bird 2001) that is considered from the point of view of its subsets of groups. The two partial groups "one group of cats ... other group", are compared with respect to the property of their color, and sentence (34) describes just one of the possible alternatives. Such a meaning could be paraphrased as "Considering all relevant cats, for the property of color $\mathrm{C}$, I believe that one.PL $e$.GROUP (of) cats are black, and others are white". The meaning of sentence (34) could be represented as:

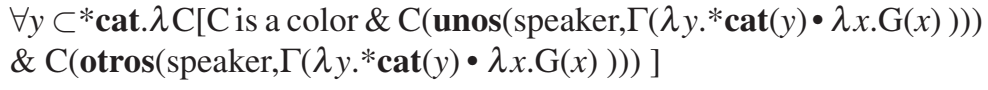

17. Topicalization of the indefinite description is not enough to enable unos-DPs to compose with an Individual-level predicate, as the sentences below seem to show:

(i) ??[Únos $\left.{ }_{\text {Topic }}\right]$ gatos son negros

b. ??Unos [gátos Topic] son negros.

c. ??[Únos gátos $\left.{ }_{\text {Topic }}\right]$ son negros. 


\section{Helena Lopez Palma}

The alternatives presupposed in the sentence with "unos ... otros" refer to the identity of the groups, and not to the number of atoms in each group. The meaning of otros gatos ("other cats"), as appears in sentence (34), can be paraphrased as "different cats from the ones previously mentioned". In the above representation we have analyzed the plural determiner otros as a function that selects as its argument a different group from the one already mentioned, which is included in the whole contrast class.

\section{Conclusions}

In this paper we have studied the semantics of the group interpretation obtained in plural-"one" DPs in Romance languages. We have suggested an account that aims at giving a uniform analysis for group denoting expressions, which also takes into consideration the role of the speaker's beliefs in the interpretation of the group. The compositional semantics we have proposed for plural-"one" DPs consists of the following aspects:

1. Weak plural-"one" DPs denote, in the unmarked reading, a fuzzy group, which we have dubbed a cluster. A cluster is an indefinite group whose reference is left underspecified by the speaker. Underspecification may be caused either by a coarse perception, or by lack of familiarity. It may also correspond to the speaker's deliberate intention to leave the referent vague.

2. The group meaning in the plural-"one" phrase is contributed by an implicit group-denoting transitive term licensed by the indefinite determiner, which selects a group-denoting category as a sortal concept.

3. The implicit group term is related to the plural noun in the unos-phase by means of a group-constitute relation (Barker 1992), which we represent as a function that maps an i-sum denoting plural nominal predicate onto a group denoting one. The access to the members can be achieved by the inversion of the function.

4. We have applied Kratzer's Perspectival Choice Function analysis to represent the denotation of the specific interpretation of plural-"one" DPs. We have suggested that the plural-"one" indefinite determiner denotes a perspectival choice function that takes a predicate denoting a set of groups and returns a unique group, which is picked by the holder of the perspective. That group may be perceived as a group or as a sum of individuals. We suggested that such an analysis enables us to represent the role of the speaker's beliefs in gathering the heterogeneous nature of the inferred knowledge needed to interpret the meaning of the group denoted by plural-"one" DPs.

In this paper we have aimed at finding an explanation for the contradiction posed by previous analyses of the Spanish indefinite determiner unos as a col- 
lectivizer word. We have suggested that a perspectival approach to compose the meaning of unos-DPs enables us to give a principled account of the problem. The parts may be accessed through the constitute function provided that the speaker is acquainted with the referent.

University of A Coruña LLF, Université Paris 7

\section{References}

Alonso Ovalle, Luis and Paula Menéndez Benito (2002). Some epistemic indefinites. In Proceedings of 33rd NELS, Makoto Kadowaki and Shigeto Kawahara (eds.), 1-12. University of Massachusetts, Amherst: GLSA.

Barker, Chris (1992). Group terms in English: Representing groups as atoms. Journal of Semantics 9: 69-93.

Bird, Alexander (2001). Scepticism and contrast classes. Analysis 61: 97-107.

Bosque, Ignacio (2001). Adjective position and the interpretation of indefinites. In Current Issues in Spanish Syntax and Semantics, J. Gutiérrez Rexach and L. Silva Villar (eds.), 17-38. Berlin: de Gruyter.

Brucart, José María (1997). Concordancia ad sensum y partitividad en español. In Contribuciones al estudio de la lingüistica hispánica: homenaje al profesor Ramón Trujillo. Manuel Almeida (coord.), vol. 1, 157-184. Barcelona: Montesinos.

Chierchia, Gennaro (2001). A puzzle about indefinites. In Semantic Interfaces. Reference, Anaphora and Aspect, Carlo Cecchetto et al. (eds.), 51-89. Stanford: CSLI Publications.

Chung, Sandra and Willian Ladusaw (2004). Restiction and Saturation. Cambridge, MA: MIT Press.

Corbett, Greville (2003). Agreement: Terms and boundaries. In The Role of Agreement in Natural Language: TLS 5 Proceedings, W. Griffin (ed.), 109-122. Texas Linguistic Forum 53.

Demonte, Violeta (2004). Merge of adjectives in DP. WECOL. LA, November 12-14.

Diesing (1992). Indefinites. Cambridge, MA: MIT Press.

Dobrovie Sorin, Carmen (1997). Types of predicates and the representation of existential readings. In Proceedings from Semantics and Linguistic Theory VII, Aaron Lawson (ed.), 117-134 . Ithaca, N.Y.: Cornell University, CLC Publications.

Dobrovie Sorin, Carmen (2004). Generic plural indefinites and (in)direct binding*. In A Handbook of French Semantics. F. Corblin and H. de Swart (eds.), 55-70. Stanford, CA: CSLI Publicacions.

Dryer, Matthew (2005). Indefinite articles. In World Atlas of Language Structures, M. Dryer, M. Haspelmath, D. Gil and B. Comrie (eds.), 158-161. Oxford: Oxford University Press.

Fenstadt, Jens E. (ed.) (1970). Thoralf Skolem. Selected works in logic. Oslo: Scandinavian University Books.

Fodor and Sag, Ivan (1982). Referential and quantificational indefinites. Linguistics and Philosophy 5: 355-398.

Gil, David (2005). Distributive numerals. In World Atlas of Language Structures, M. Dryer, M. Haspelmath, D. Gil and B. Comrie (eds.), 222-225. Oxford: Oxford University Press.

Givon, Talmy (1981). On the development of the numeral 'one' as an indefinite marker. In Folia Linguistica Historica, 2: 35-53

Gutiérrez Rexach, Javier (2001). The semantics of Spanish plural existential determiners and the dynamics of judgment types. Probus 13: 113-154.

Haspelmath, Martin (1997). Indefinite Pronouns. Oxford. Oxford University Press.

Heim, Irene (1982). The semantics of definite and indefinite noun phrases. Ph.D. dissertation. UMass. 


\section{Helena Lopez Palma}

Kratzer, Angelika. (1998). Scope or pseudo-scope? Are there wide-scope indefinites? In Events in Grammar, S. Rothstein (ed.), 163-196. Dordrecht: Kluwer.

Krifka, Manfred. (1999). Additive particles under stress. In Proceedings of SALT 8, 111-128. Cornell.

Laca, Brenda (1996). Acerca de la semántica de los plurales escuetos del español. In El sustantivo sin determinación, I. Bosque (ed.), 241-268. Madrid: Visor.

Laca, Brenda and Tasmowski, Liliane (1996). Indefini et quantification. In Recherches Linguistiques de Vincennes, 25: 107-128.

Ladusa, William (1994). Thetic and categorical, state and individual, weak and strong. In Proceedings of SALT IV, M. Harvey and L. Santelmann (eds.), 220-229. Ithaca, NY: CLC Publications, Cornell University.

Landman, Fred (2004). Indefinites and the Type of Sets. Oxford: Blackwell.

Lasersohn, Peter (1995). Plurality, Conjunction and Events. Dordrecht: Kluwer.

Link, Godehard (1983). The logical analysis of plural and mass terms: a lattice-theoretical approach. In Meaning, Use, and Interpretation of Language, R. Bäuerle et al. (eds.), 302-323. Berlin: Walter de Gruyter.

- (1984). Hydras. On the logic of relative clauses constructions with multiple heads. In Varieties of Formal Semantics, F. Landmann and F. Veltmann (eds.), 245-257. Dordrecht: Foris. Reprinted in G. Link Algebraic Semantics in Language and Philosophy. Stanford: CSLI Pub. $1998,77-84$.

Mallinson, Graham (1986). Rumanian. London: Croom Helm.

Marti, Luisa (2006). The semantics of plural indefinites in Spanish and Portuguese. 16th Colloquium on Generative Grammar. Universidad Autonoma de Madrid, Spain, April 20-22.

McNally, Louise (1995). Bare plurals in Spanish are interpreted as properties. In Formal Grammar, G. Morril and R. Oehrle (eds.), 197-222. Barcelona: Universitat Politecnica de Catalunya.

- (1998). Existential sentences without existential quantification. Linguistics and Philosophy 21: 353-392.

Milsark, Gary (1977). Towards an explanation of certain peculiarities in the existential construction in English. Linguistic Analysis 3 (1): 1-29.

Partee, Barbara (1989). Binding implicit variables in quantified contexts. CLS 25: 342-365. Reprinted in Compositionality in Formal Semantics: Selected Papers by Barbara H. Partee, B. Partee (2004), 259-281. Oxford: Blackwell Publ.

Partee, Barbara, Alice ter Meulen and Robert Wall (1993). Mathematical Methods in Linguistics. Dordrecht: Kluwer Academic Publishers.

Plank, Frans (1994). The unlikely plurals of one in Bavarian and Miskito. In Agreement Gender Number Genitive (EUROTYP Working Papers VII/23): 59-79.

Reinhart, Tania (1997). Quantifier scope: How Labor is divided between quantifier raising and choice-functions. Linguistics and Philosophy 20: 335-397.

Safir, Kent and Tim Stowell (1989). Binominal each. Proceedings of NELS 18, J. Blevins and J. Carter (eds.), 426-450. Amherst, MA: University of Massachusetts, GLSA Publications.

Salamanca, Danilo (1988). Elementos de gramática del Miskito. Ph.D. dissertation, Massachusetts Institute of Technology, Cambridge.

Villalta, Elisabeth (1994). Plural indefinites in Spanish and distributivity. Ms. University of Paris 7. Winter, Yoad 2001 Flexibility Principles in Boolean Semantics. Cambridge, MA: MIT Press. 